\title{
Computational Form-Finding Analysis in Richmond's Surface with Different Prestress
}

\author{
Yee Hooi Min and Fatin Nurqamarulhuda Binti Ismail
}

\begin{abstract}
Form-finding of fabric surface bordered by Richmond's has been investigated. In this study, the possibility of adopting the form of Richmond's as surface shape in tensioned fabric structure under different prestress values has been studied. The combination of shape and internal forces for the purpose of stiffness and strength is an important feature of fabric surface. For this purpose, form-finding needs to be carried out. Nonlinear analysis method has been used for form-finding analysis of the fabric in the form of Richmond's minimal surface. Richmond's minimal surface models are analyzed with two different values of prestress which are $3000 \mathrm{~N} / \mathrm{m}$ and $5000 \mathrm{~N} / \mathrm{m}$. The average warp and fill stresses deviation for all models presented are less than 0.01 which indicates the model can serve as reference to the engineers or architects in the selection of proper surface parameter to achieve a structurally viable surface. As a result, this study is expected to lead the improvement of rural basic infrastructure, economic gains, sustainability of built environment and green technology initiative.
\end{abstract}

Index Terms: Form-finding, fabric, prestress, Richmond's.

\section{INTRODUCTION}

The basic component to provide a roofing stricture of tensioned fabric structure (TFS) is composed of fabric structure as structural member, seam, supporting system and cable. [1] stated that TFS are the composition of tensioned fabrics that joined together at seams and tensioned through cable to rigid supporting system to provide roofing structure.

The materials used for membranes generally consist of a woven fabric coated with a polymeric resin. The two most commonly used membrane types are poly tetra fluoro ethylene (PTFE) coated plain weave glass-fibre fabrics and PVC coated plain weave nylon or polyester fabrics. A fabric is coated when a weather tight structure required. In that case, the fabric consists of three layers - one layer of woven yarns and two layers of coating materials. The coating protects the fabric from UV radiation degradation, rainwater and atmospheric moisture. Fabric is made of woven yarns. Warp and fill yarns that are twisted together. The yarns are weaved in such a way that threads are perpendicular to one another and they are alternately passing over and under each other. Long straight yarns are called warp yarns and the direction parallel to the warp yarns are called warp direction; whereas perpendicular yarns are called fill yarns and they are weaved alternately over and under the warp yarns. The

Revised Manuscript Received on September 22, 2019.

Yee Hooi Min, Faculty of Civil Engineering, Universiti Teknologi MARA, Penang, Malaysia.

Fatin Nurqamarulhuda Binti Ismail, Faculty of Civil Engineering, Universiti Teknolog,i MARA, Penang, Malaysia. direction that is parallel to the fill yarns are called fill direction.

Form-finding using nonlinear analysis method or soap film models in the form of two saddle-shaped tensioned fabric structure model, cable reinforced double Chinese hat tensioned fabric structure model, cable reinforced tent Hüfingen tensioned fabric structure model, Catenoid, Helicoid, Scherk, Enneper, Moebius Strip, Costa, half-Costa in XZ and YZ plane, Oval, Egg, Monkey Saddle, Chen-Gackstatter, Handkerchief, cable reinforced Bour's, Richmond's (only considered 2000N/m prestress), Bour's, and Thomsen TFS models have been carried out by [1-22]. The objectives of this study are to determine initial equilibrium shape of TFS in the form of Richmond's minimal surface and propose tensioned fabric structures in the form of Richmond's minimal surface in different prestressed value of $3000 \mathrm{~N} / \mathrm{m}$, and $5000 \mathrm{~N} / \mathrm{m}$ using nonlinear analysis method proposed by [1].

\section{GENERATION OF RICHMOND'S MINIMALSURFACE IN TENSIONED FABRIC STRUCTURE}

Richmond's surface as shown in Fig. 1 is a minimal surface with one planar end. It can be expressed as a family of surfaces in polar coordinates as (1) from [23]. The creation of new model for tensioned fabric structure however cannot be described by simple mathematical method but to be form using form-finding analysis.

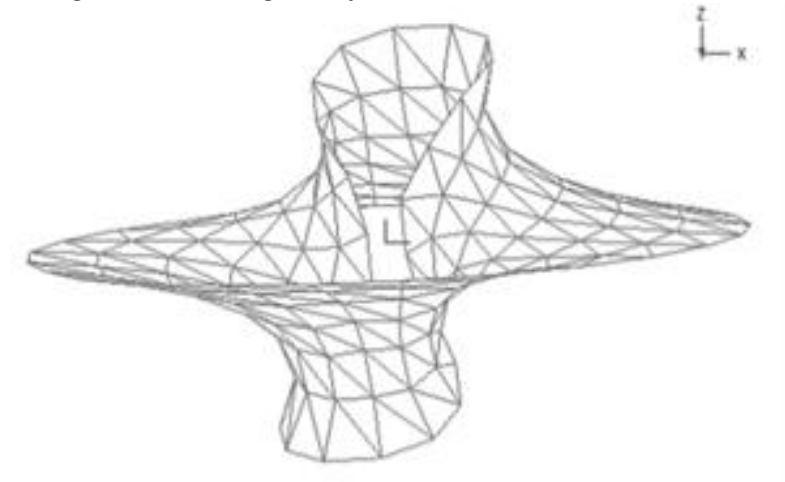

Fig. 1: Richmond's surface

$$
\begin{aligned}
& x:=-\frac{\cos (\mathrm{t}+\theta)}{2 r}-\frac{r^{1+2 n} \cdot \cos (\mathrm{t}-(1+2 n) \cdot \theta)}{2+4 n} \\
& y:=-\frac{\sin (\mathrm{t}+\theta)}{2 r}+\frac{r^{1+2 n} \cdot \sin (\mathrm{t}-(1+2 n) \cdot \theta)}{2+4 n}
\end{aligned}
$$




$$
z:=\frac{1}{n} r^{n} \cos (\mathrm{t}-n \cdot \theta)
$$

where $\mathrm{n}$ is the degree of the surface, $\mathrm{t}$ is a parameter that creates a family of surfaces, $r \in[0.35,1.2]$, and $\theta \in[0,2 \pi]$. The changing value of $r$ parameter will affect the shape of the generated shape.

In this study, form-finding using nonlinear analysis method in the shape of Richmond's with parameters $r=0.44$, $\mathrm{t}=1.11 ; r=0.54, \mathrm{t}=1.01$, and $r=0.64, \mathrm{t}=0.91$ have been carried out with prestress value of $3000 \mathrm{~N} / \mathrm{m}$, and $5000 \mathrm{~N} / \mathrm{m}$. From this study, the software ADINA [24] has been used for the purpose of model generation. The number of nodes coordinates and number triangular elements involved are 175, and 288, respectively. The shear stress is kept zero. Tensile modulus in warp direction, $\mathrm{E}_{\mathrm{Wt}}$ is $429200 \mathrm{~N} / \mathrm{m}$, while the tensile modulus in fill direction, $\mathrm{E}_{\mathrm{Ft}}$ is $337910 \mathrm{~N} / \mathrm{m}$, shear modulus, $G_{t}$ is $64700 \mathrm{~N} / \mathrm{m}$, and Poisson's ratio corresponds to warp direction, $\mathrm{v}_{\mathrm{W}}$ is 0.84 , and Poisson's ratio corresponds to fill direction, $\mathrm{v}_{\mathrm{F}}$ is 0.57 .

\section{COMPUTATIONAL FORM-FINDING USING NONLINEAR ANAL YSIS METHOD}

Authors of the [1] stated the principle of nonlinear analysis method is based on the large displacement finite element formulation used for analysis of structural behavior under external loads. Since the method can be used for both the initial equilibrium problem and load analysis, the approach using nonlinear analysis is quite common. The basic equation used is expressed as (2):

$$
\left({ }_{0}^{t} \boldsymbol{K}_{L}+{ }_{0}^{t} \boldsymbol{K}_{G}\right) \boldsymbol{u}={ }^{t+\Delta t} \boldsymbol{F}-{ }_{0}^{t} \boldsymbol{f}
$$

where ${ }_{0}^{t} \boldsymbol{K}_{L}$ is linear strain incremental stiffness matrix, ${ }_{0}^{t} \boldsymbol{K}_{G}$ is nonlinear strain incremental stiffness matrix, ${ }_{0}^{t} \boldsymbol{f}$ is vector internal forces, ${ }^{t+\Delta t} \boldsymbol{F}$ is load vector, and $\boldsymbol{u}$ is vector of increment in displacement.

A nonlinear finite element analysis program by [1] for the analysis of tensioned fabric structures has been used in this study. The procedure adopted is based on the work by [1]. 3 -node plane stress element has been used as element to model the surface of TFS. All x, y, and z translation of nodes lying along the boundary edge of the Richmond's minimal surface have been restrained. The member pretension in warp and fill direction, is $3000 \mathrm{~N} / \mathrm{m}$ or $5000 \mathrm{~N} / \mathrm{m}$, respectively. The shear stress is zero. Two stages of analysis were involved in the procedures of form-finding in one cycle proposed by [1]. First stage (denoted as SF1) is analysis which starts with an initial assumed shape in order to obtain an updated shape for initial equilibrium surface. The initial assumed shape can be obtained from any pre-processing software, and reference [1] is chosen for this study. This is then followed by the second stage of analysis (SS1) aiming at checking the convergence of updated shape obtained at the end of stage (SF1). During stage (SF1), artificial tensioned fabric properties, E with very small values are used. Both warp, and fill tensioned fabric stresses are kept constant. In the second stage of (SS1), the actual values of tensioned fabric properties are used. Resulting warp, and fill tensioned fabric stresses are checked at the end of the analysis against prescribed tensioned fabric stresses. Then, iterative calculation has to be carried out in order to achieve convergence where the criteria adopted is that the average of warp, and fill stress deviation should be $<0.01$. The resultant shape at the end of iterative step $\mathrm{n}(\mathrm{SSn})$ is considered to be in the state of initial equilibrium under the prescribed warp, and fill stresses and boundary condition if difference between the obtained, and the prescribed membrane stresses relative to the prescribed stress is negligibly small. Such checking of difference in the obtained, and prescribed stresses has been presented in the form of total stress deviation in warp, and fill direction versus analysis step. As a first shape for the start of form-finding procedure adopted in this study, initial assumed shape is needed. For the generation of such initial assumed shape, knowledge of the requirement of anti-clastic nature of TFS is used. The incorporation of anti-clastic feature into the model will help to produce a better initial assumed shape. Form-finding on TFS models in the form of Richmond's minimal surface have been carried out. The $r=0.44, \mathrm{t}=1.11$; $r=0.54, \mathrm{t}=1.01$, and $r=0.64, \mathrm{t}=0.91$ have been studied.

\section{RESULTS AND DISCUSSION}

For computational form-finding analysis, initial equilibrium shape is determined. Fig. 2 shows the initial assumed shape (before analysis) and initial equilibrium shape (after analysis) of Richmond's minimal surface (prestress $3000 \mathrm{~N} / \mathrm{m}$ ) with $r=0.44, \mathrm{t}=1.11$, respectively. Variation of total stress deviation in warp, and fill direction versus stress analysis stage of Richmond's minimal surface with $r=0.44, \mathrm{t}=1.11$ as shown in FiG. 3. The Richmond's minimal surface with $r=0.44, \mathrm{t}=1$.11 has been found to converge with least square error of total warp, and fill stress deviation less than 0.01 . Richmond's minimal surface with $r=0.44, \mathrm{t}=1.11$ with prestress of $5000 \mathrm{~N} / \mathrm{m}$ as it forms similar shape with prestress values of $3000 \mathrm{~N} / \mathrm{m}$.

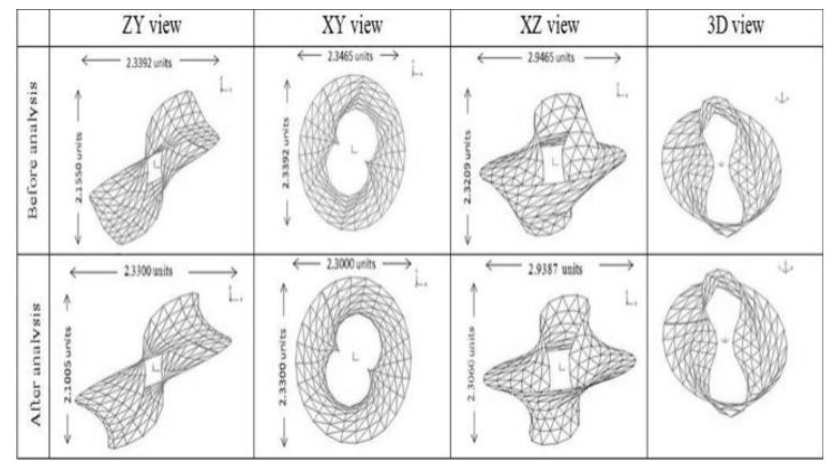

Fig.2: Initial assumed shape, and initial equilibrium shape of Richmond's minimal surface (prestress 3000N/m) with $r=0.44, \mathrm{t}=1.11$ 


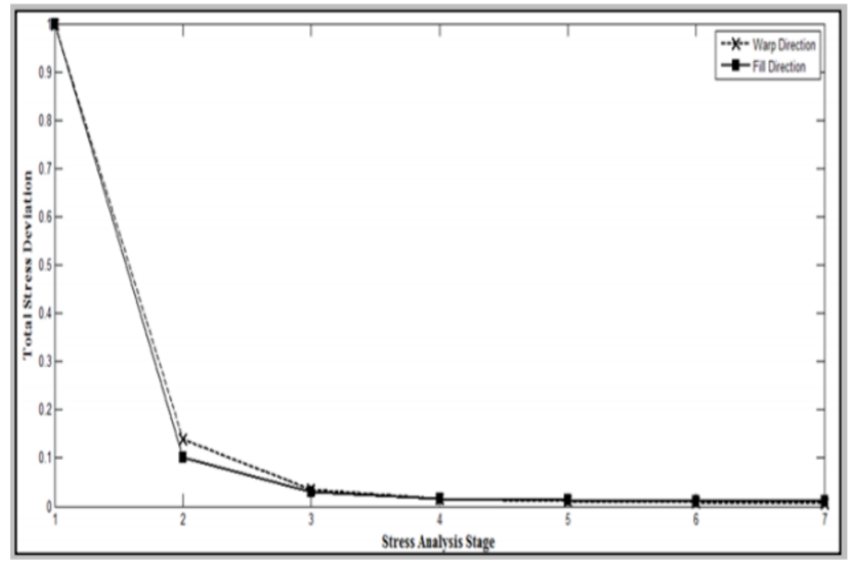

Fig.3: Variation of total stress deviation in warp and fill direction versus stress analysis stage of Richmond's minimal surface (prestress $3000 \mathrm{~N} / \mathrm{m}$ ) with $r=0.44, \mathrm{t}=1.11$

Fig.4 shows the initial assumed shape (before analysis), and initial equilibrium shape (after analysis) of Richmond's minimal surface (prestress $3000 \mathrm{~N} / \mathrm{m}$ ) with $r=0.54, \mathrm{t}=1.01$, respectively. Variation of total stress deviation in warp, and fill direction versus stress analysis stage of Richmond's minimal surface with $r=0.54, \mathrm{t}=1.01$ as shown in Fig. 5 . The Richmond's minimal surface with $r=0.54, \mathrm{t}=1.01$ has been found to converge with least square error of total warp, and fill stress deviation less than 0.01. Richmond's minimal surface with $r=0.54, \mathrm{t}=1.01$ with prestress of $5000 \mathrm{~N} / \mathrm{m}$ as it forms similar shape with prestress values of $3000 \mathrm{~N} / \mathrm{m}$.

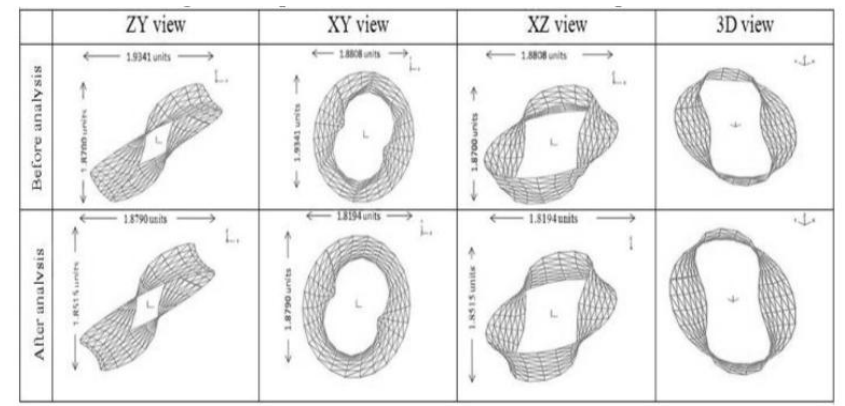

Fig. 4: Initial assumed shape, and initial equilibrium shape of Richmond's minimal surface (prestress 3000N/m) with $r=0.54, \mathrm{t}=1.01$

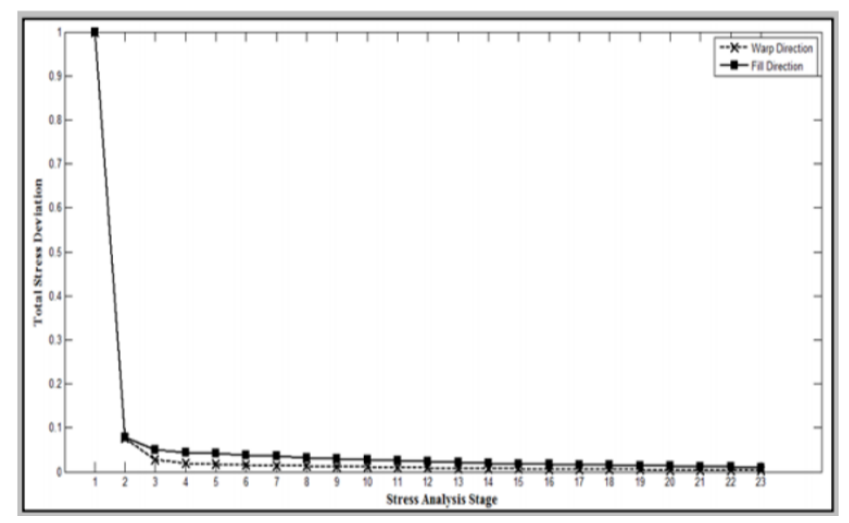

Fig.5: Variation of total stress deviation in warp and fill direction versus stress analysis stage of Richmond's minimal surface (prestress $3000 \mathrm{~N} / \mathrm{m}$ ) with $r=0.54, \mathrm{t}=1.01$
Fig.6 shows the initial assumed shape (before analysis) and initial equilibrium shape (after analysis) of Richmond's minimal surface (prestress $3000 \mathrm{~N} / \mathrm{m}$ ) with $r=0.64, \mathrm{t}=0.91$, respectively. Variation of total stress deviation in warp, and fill direction versus stress analysis stage of Richmond's minimal surface with $r=0.64, \mathrm{t}=0.91$ as shown in Fig. 7 . The Richmond's minimal surface with $r=0.64$, $\mathrm{t}=0.91$ has been found to converge with least square error of total warp, and fill stress deviation less than 0.01. Richmond's minimal surface with $r=0.64, \mathrm{t}=0.91$ with prestress of $5000 \mathrm{~N} / \mathrm{m}$ as it forms similar shape with prestress values of $3000 \mathrm{~N} / \mathrm{m}$.

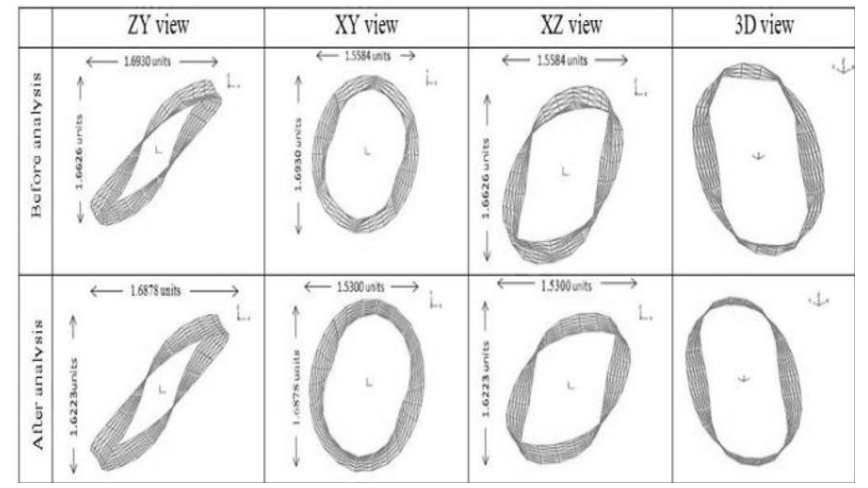

Fig. 6: Initial assumed shape, and initial equilibrium shape of Richmond's minimal surface (prestress 3000N/m) with

$$
r=0.64, \mathrm{t}=0.91
$$

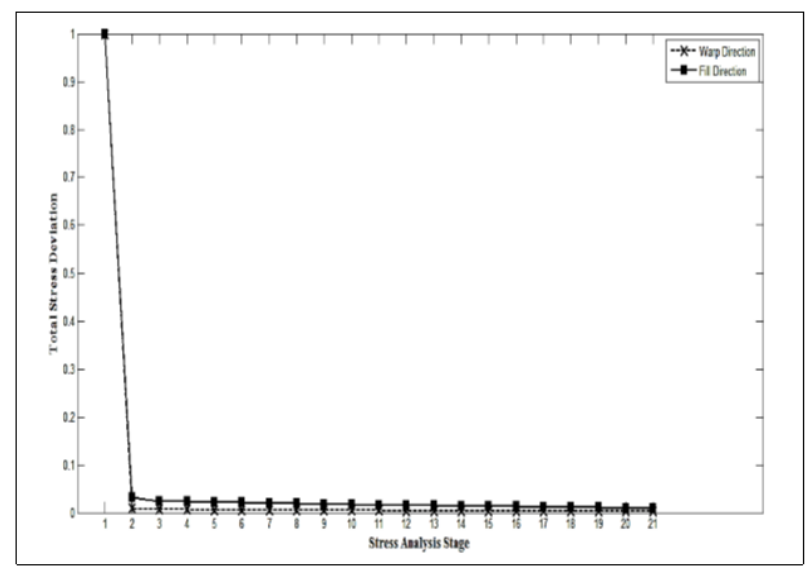

Fig.7: Initial assumed shape, and initial equilibrium shape of Richmond's minimal surface (prestress $3000 \mathrm{~N} / \mathrm{m}$ ) with $r=0.64, \mathrm{t}=0.91$

\section{CONCLUSIONS}

Form-finding of TFS in the form of Richmond's minimal surface with prestress of $3000 \mathrm{~N} / \mathrm{m}$, and $5000 \mathrm{~N} / \mathrm{m}$ has been carried out successfully using the procedure adopted which is based on nonlinear analysis method. The results from this computational study show that TFS in the form Richmond's minimal surface with prestress of $3000 \mathrm{~N} / \mathrm{m}$, and $5000 \mathrm{~N} / \mathrm{m}$ of are structurally viable surface form to be considered.

\section{ACKNOWLEDGMENT}

The researchers wish to thank to Universiti Teknologi MARA for the administrative support. 


\section{REFERENCES}

1. H.M.Yee, "A computational strategy for form-finding of tensioned fabric structure using nonlinear analysis method," Ph. D. dissertation, School of Civil Engineering, Universiti Sains Malaysia, Pulau Pinang, Malaysia, 2011.

2. H.M. Yee, K.K. Choong, and J.Y. Kim, "Form-finding analysis of tensioned fabric structures using nonlinear analysis method," Advanced Materials Research, vol. 243-249, 2011, pp. 1429-1434.

3. H.M. Yee, J.Y. Kim, and M. Mohd Noor, "Tensioned fabric structures in oval form," Applied Mechanics and Materials, vol. 405-408, 2013, pp. 1008-1011.

4. M. Mohd Noor, H.M. Yee, K.K. Choong, and H. Abdul Hamid, "Tensioned membrane structures in the form of egg shape," Applied Mechanics and Materials, vol. 405-408, 2013, pp. 989-992.

5. H.M. Yee, and K.K. Choong, "Form-finding of tensioned fabric structure in the shape of Möbius Strip," Iranica Journal of Energy \& Environment 4 \{(3) Geo-hazards and Civil Engineering)\}, 2013, pp. 251-257.

6. H.M. Yee, and M.A. Samsudin, "Development and investigation of the Moebius Strip in tensioned membrane structures," WSEAS Transactions on Environment and Development, vol. 10, 2014, pp. 145-149.

7. H.M. Yee, and M.A. Samsudin, "Mathematical and computational analysis of Moebius Strip," International Journal of Mathematics and Computers in Simulation, vol. 8, 2014, pp. 197-201.

8. H.M. Yee, H. Abdul Hamid, and M. Abdul Hadi, "Computer investigation of tensioned fabric structure in the form of Enneper minimal surface," Applied Mechanics and Materials, vol. 754-755, 2015), pp. 743-746.

9. H.M. Yee, K.K. Choong, and M. Abdul Hadi, "Sustainable development of tensioned fabric green structure in the form of Enneper," International Journal of Materials, Mechanics and Manufacturing, vol. 3, no. 2, 2015, pp. 125-128.

10. H.M. Yee, and M.N. Abdul Hadi, "Soap film Enneper model in structure engineering," Proceedings of the International Conference on Advanced Materials, Structures and Mechanical Engineering, Incheon, South Korea, 2015.

11. H.M. Yee, and M. Abdul Hadi, "Tensioned fabric structures with surface in the form of Chen-Gackstatter and Monkey Saddle," International Journal of Structural and Civil Engineering Research, vol. 4, no. 4, 2015, pp. 331-335.

12. H.M. Yee, and M.N. Abdul Hadi, "Enneper in tensioned fabric structures engineering development," $17^{\text {th }}$ International Conference on Mathematical and Computational Methods in Science and Engineering, Kuala Lumpur, Malaysia, 2015.

13. H.M. Yee, M.N. Abdul Hadi,, K.A. Ghani, and N.H.A. Hamid, “ Tensioned fabric structures with surface in the form of Monkey Saddle surface," Proceedings of the $2^{\text {nd }}$ International Conference of Advanced Materials, Mechanical and Structural Engineering, Je-ju Island, South Korea, 2015

14. H.M. Yee, and K.K. Choong, "A computational mechanics using nonlinear analysis method in tensioned fabric structures," International Journal of Mechanics, vol. 10, 2016, pp. 261-265.

15. M. Abdul Hadi, H.M. Yee, K. Abd Ghani, and H. Abdul Hamid, "Architectural tensioned fabric structure in Monkey saddle form," International Journal of Control Theory and Applications, vol. 9, no. 6, 2016, pp. 2753-2758.

16. H.M. Yee, and M.N. Abdul Hadi, "Tensioned fabric structures with surface in the form of Chen-Gackstatter," MATEC Web Conferences, vol. 64, pp.1-5, 2016.

17. H.M. Yee, N.A. Abd Malek, and N.S.A. Aziz, "Form-finding of sustainable cable reinforced tensioned fabric structure in different pre-stress," 35th Conference of ASEAN Federation of Engineering Organisations, Towards a Sufficiency Economy: Pathways to Sustainable Development, Bangkok, Thailand, 2017.

18. M.H. Wan Ibrahim, M.N. Abdul Hadi, and H.M. Yee, "Form-finding using nonlinear analysis method in tensioned fabric structure in the form of Handkerchief surface," Journal of Physics, vol. 995, 2018, pp. 1-9.

19. H.M. Yee, A.P. Norman, A. Azura, N. Hamzah, N.I. Zainuddin, and M.I.F. Rozli, "Computational form-finding analysis in the shape of Bour's," WSEAS Transactions on Applied and Theoretical Mechanics, vol. 13, 2018, pp. 140-149.

20. M.H. Wan Ibrahim, M.N. Abdul Hadi, and H.M. Yee, "Form-finding of Thomsen surface using nonlinear analysis method," Journal of Physics, vol. 995, 2018, pp. 1-8

21. H.M. Yee, N.Z. Arabi, N.A. Abd Malek, R. Rohim, and A.A. Yusuff, "Computational study on tensioned fabric structure in the form of Richmond's,” Key Engineering Materials, vol. 777, 2018, pp. 538-542.

22. H.M. Yee, and M.N. Abdul Hadi, "Form-finding with and without cable reinforced Thomsen surface in tensioned fabric structure," Journal of Physics, vol. 1174, 2019, pp. 1-7.
23. P. Nylander. (2019, January 4). Richmond's Minimal Surface [Online]. Available:https://nylander.wordpress.com/2007/06/06/richmond $\%$ E2\%80 $\% 99$ s-minimal-surface/

24. ADINA (2003) System 8.1. (1994-2003) ADINA (2003)-AUI. Version 8.1. ADINA (2003) R\&D INC.

\section{Authors Profile}

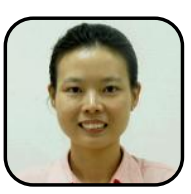

Yee Hooi Min graduated with a doctorate degree Structural Engineering, Master of Science Engineering and Bachelor of Engineering (Honours) Civil Engineering from the Universiti Sains Malaysia, Pulau Pinang, Malaysia. She was a fellow at Universiti Sains Malayisa. After graduating, she worked as senior lecturer at Faculty of Civil Engineering, Universiti Teknologi MARA, Pulau Pinang, Malaysia and was promoted to Associate Professor on 2017. Her research interest is Computational Mechanics, Computational Analysis of Shell and Spatial Structures, Nonlinear Analysis, Engineering Education and Architectural Engineering. She is a supervisor of $\mathrm{PhD}$ and Master students. She is an external examiner for the postgraduate student. She is also certified as an 'International Professional Engineer', 'APEC Engineer', 'ASEAN Engineer', Professional Engineer with Practising Certificate of Board of Engineers Malaysia, Corporate Member of The Institution of Engineers Malaysia, The ASEAN Federation of Engineering Organisations, Construction Industry Development Board Malaysia and Concrete Society of Malaysia. She is an evaluation panel Engineering Accreditation Council and Engineering Technology Accreditation Council. She is a Professional Engineer Interviewer/Examiner for The Institution of Engineers Malaysia since 2016. She is an Executive Committee of The Institution of Engineers Malaysia (Penang Branch) from 2014-16 and 2017-2019. For her much appreciated leadership and contributions towards excellence in engineering, society enhancement and nation development; the international Engineering Fraternity conferred Associate Professor Ir. Dr. Yee the ASEAN Federation of Engineering Organisations (AFEO)'s Honorary Member Award by AFEO Governing Board which carries the abbreviation M.AFEO after her name on 2018. She conferred the status of International Professional Engineer and APEC Engineer by EMF International Professional Engineer and Asia-Pacific Economic Cooperation, respectively on 23 November 2017 together with the designatory letters IntPE and APEC ENGINEER. She conferred ASEAN Engineer award by the AFEO Governing Board together with the designatory letters ASEAN Eng. on 2015. She is awarded Universiti Teknologi MARA 'Excellent Service Award'. She as a vice-chairman for the 2 international conference have been held in Malaysia on 2015. She is The Conference of the ASEAN Federation of Engineering Organisations (CAFEO) organizer committee on 2015. She has organized a technical visit to South Korea and Russia on 2016 and 2018, respectively under Women Engineers Section in IEM (Penang branch). She is an earthquake design sub-committee from IEM (Penang branch) on 2019.

Associate Professor Ir .Dr. Yee has obtained 16 awards in Invention, Innovation and Research Design Platform and has published 86 up-to-date publications. Her other achievements include invitations as Keynote Speaker, International Invited Speaker, International Visiting Professor, Session Chairman and technical committee to over international and national technical conferences and seminars worldwide which include those in Czech Republic United Kingdom, Ireland, Spain, Australia, Republic of China, Indonesia, Thailand and Malaysia.

Fatin Nurqamarulhuda Binti Ismail was undergraduated degree student from Universiti Teknologi MARA, Penang, Malaysia. 